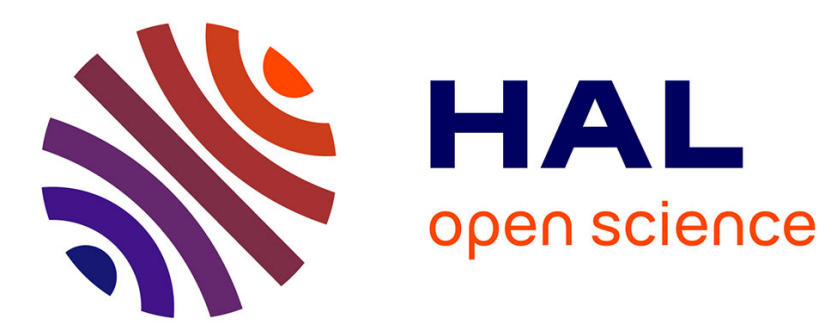

\title{
VUV photoionization and dissociative photoionization spectroscopy of the interstellar molecule aminoacetonitrile: Theory and experiment
}

\author{
A. Bellili, M. Schwell, Y. Bénilan, N. Fray, M.-C. Gazeau, M. Mogren
}

Al-Mogren, J.-C. Guillemin, L. Poisson, M. Hochlaf

\section{To cite this version:}

A. Bellili, M. Schwell, Y. Bénilan, N. Fray, M.-C. Gazeau, et al.. VUV photoionization and dissociative photoionization spectroscopy of the interstellar molecule aminoacetonitrile: Theory and experiment. Journal of Molecular Spectroscopy, 2015, 315, pp.196-205. 10.1016/j.jms.2015.05.008 . hal-01215480

\author{
HAL Id: hal-01215480 \\ https://hal.science/hal-01215480
}

Submitted on 12 Nov 2015

HAL is a multi-disciplinary open access archive for the deposit and dissemination of scientific research documents, whether they are published or not. The documents may come from teaching and research institutions in France or abroad, or from public or private research centers.
L'archive ouverte pluridisciplinaire HAL, est destinée au dépôt et à la diffusion de documents scientifiques de niveau recherche, publiés ou non, émanant des établissements d'enseignement et de recherche français ou étrangers, des laboratoires publics ou privés. 


\title{
VUV photoionization and dissociative photoionization spectroscopy of the interstellar molecule aminoacetonitrile: theory and experiment
}

\author{
A. Bellili, ${ }^{1)}$ M. Schwell, ${ }^{2),}$ a) Y. Bénilan, ${ }^{2)}$ N. Fray, ${ }^{2)}$, M.-C. Gazeau, ${ }^{2)}$ M. Mogren Al-Mogren, ${ }^{3)}$ \\ J.-C. Guillemin, ${ }^{4)}$ L. Poisson, ${ }^{5)}$ M. Hochlaf ${ }^{1), \text { a) }}$
}

1) Université Paris-Est, Laboratoire Modélisation et Simulation Multi Echelle, MSME UMR 8208 CNRS, 5 bd Descartes, 77454 Marne-la-Vallée, France.

2) Laboratoire Interuniversitaire des Systèmes Atmosphériques (LISA), UMR 7583 CNRS, Universités Paris-Est Créteil et Paris Diderot, Institut Pierre et Simon Laplace, 61 Avenue du Général de Gaulle, 94010 Créteil, France

3) Chemistry Department, Faculty of Science, King Saud University, P.O. Box 2455, Riyadh 11451,

$$
\text { Kingdom of Saudi Arabia }
$$

4) Institut des Sciences Chimiques de Rennes, École Nationale Supérieure de Chimie de Rennes, CNRS, UMR 6226, 11Allée de Beaulieu, CS 50837, 35708 Rennes Cedex 7, France.

5) Laboratoire Francis Perrin, CNRS URA 2453, CEA, IRAMIS, LIDyL, Bât 522, F-91191

Gif/Yvette, France.

a) To whom correspondence should be addressed:

MS: Tel. +33145171521. Electronic mail: martin.schwell@lisa.u-pec.fr

MH: Tel. +33160957319. Electronic mail: hochlaf@ univ-mlv.fr 


\begin{abstract}
Aminoacetonitrile (AAN) is a key compound in astrochemistry and astrobiology. We present a combined theoretical and experimental investigation concerning the single photoionization of gas-phase AAN and the fragmentation pathways of the resulting cation. At present, we measured photoelectron photoion coincidence (PEPICO) spectra in the 9.8 to $13.6 \mathrm{eV}$ energy regime using synchrotron radiation as exciting light source. In order to interpret the VUV experimental data obtained, we explored the ground potential energy surface (PES) of AAN and of its cation using standard and explicitly correlated quantum chemical methodologies. This allowed us to deduce accurate thermochemical data for this molecule. We also determined, for the first time, the adiabatic ionization energy of AAN to lie at $\mathrm{AIE}=(10.085 \pm 0.03) \mathrm{eV}$. The unimolecular decomposition pathways of the resulting $\mathrm{AAN}^{+}$parent cation are also investigated. The appearance energies of five fragments are determined for the first time, with $30 \mathrm{meV}$ accuracy. Interestingly, our work shows the possibility of the formation of both $\mathrm{HCN}$ and $\mathrm{HNC}$ isomeric forms. The implications for the evolution of prebiotic molecules under VUV irradiation are briefly discussed.
\end{abstract}




\section{Introduction}

Recently, substantial progress in astrophysical observation has permitted the detection of many complex molecules in the interstellar medium (ISM) and in circumstellar envelopes. Observed molecules can be used as sensitive indicators to probe astrophysical processes such as accretion of matter in young stellar objects or plasma jets, for example. Complex chemical species give us insight into the relationship between molecular clouds and planetary formation systems embedded in these clouds. The utility of molecules comes from both their spectra, which are highly instructive, and the chemical network they constitute.

To date, more than 170 different molecules have been detected and $1 / 3$ of them contain more than 6 atoms [1]. Most of these molecular identifications were accomplished after comparison of laboratory spectra to observations of interstellar surveys. A recent survey using the IRAM $30 \mathrm{~m}$ telescope of Sagittarius B2(N) and (M), which are objects where many complex organic molecules are observed, is found in ref. [2]. Of particular interest for astrobiology and the study of prebiotic chemistry in space are the recent detections of acetamide [3] the biggest molecule having a peptide-like bond, and aminoacetonitrile $\left(\mathrm{H}_{2} \mathrm{NCH}_{2} \mathrm{CN}\right.$ denoted hereafter as "AAN") $[2,4]$ which is a direct precursor of the simplest amino acid glycine. The presence of AAN in interstellar space strongly suggests that the Strecker reaction, i.e. the reaction between an aldehyde, $\mathrm{HCN}$ and $\mathrm{NH}_{3}$ (see refs. [5a,b] and reaction 1) actually occurs, certainly in the condensed phase of interstellar grains and/or ices:

$$
\mathrm{RHC}=\mathrm{O}+\mathrm{HCN}+\mathrm{NH}_{3} \rightarrow \mathrm{H}_{2} \mathrm{O}+\mathrm{H}_{2} \mathrm{NCH}(\mathrm{R}) \mathrm{CN}
$$

Indeed, this reaction and related pathways are thought to be a realistic and solid scenario for the formation of compounds like AAN and other prebiotic nitriles in the ISM $[6,7,8,9,10]$. The hydrolysis of such nitriles can lead to the formation of amino acids and, in the case of $\mathrm{H}_{2} \mathrm{NCH}_{2} \mathrm{CN}$ $(\mathrm{R}=\mathrm{H}$ in reaction 1), glycine will be formed. This scenario has been confirmed by laboratory astrophysics measurements. For example, Elsila et al. [6] irradiated interstellar ice analogues with vacuum UV radiation from a hydrogen discharge lamp. The ices consisted of mixtures of $\mathrm{H}_{2} \mathrm{O}, \mathrm{CH}_{3} \mathrm{OH}$ and $\mathrm{HCN}$ in various ratios at about $20 \mathrm{~K}$. They observed formation of the three amino acids glycine, alanine and serine under these conditions. The possible mechanisms, involving also AAN as 
intermediate, are discussed in their work. In a similar study, Danger et al. [9] observed the formation of AAN during warming of $\mathrm{CH}_{2} \mathrm{NH} / \mathrm{NH}_{3} / \mathrm{HCN}$ ices prepared at $20 \mathrm{~K}$ (but without action of UV photons). Density functional theory (DFT) calculations at the B3LYP/6-31+G(d,p) level have been performed too in order to study the reactions $\mathrm{CH}_{2} \mathrm{NH}+\mathrm{HCN} \rightarrow \mathrm{NH}_{2} \mathrm{CH}_{2} \mathrm{CN}$ and $\mathrm{CH}_{2} \mathrm{NH}+\mathrm{HNC} \rightarrow \mathrm{NH}_{2} \mathrm{CH}_{2} \mathrm{CN}$, in the gas phase and on icy grain surfaces [8]. Three gas phase bimolecular reaction mechanisms are identified in this study, with high barriers. However, according to their results, these barriers are significantly reduced when model icy surfaces or water molecules act as catalysts.

Molecular compounds involved in Strecker type reactions are therefore of utmost importance for astrochemistry and astrobiology. However, their gas phase spectroscopic and photophysical properties are very often not well characterized in the laboratory. This is especially true for the UV and VUV spectroscopy of AAN for which basic laboratory data are truly scarce. To the best of our knowledge, only a HeI photoelectron spectrum (with unknown resolution and energy precision) [11] and a theoretical simulation at the MP2/TZVP level of theory [12] of the UV/Vis absorption spectrum are found in the literature. In the HeI photoelectron spectrum at least 6 ionic states are observed, with vertical ionization energies found at $10.65,12.65,13.3,14.85,15.0$ and $17.8 \mathrm{eV}$ [11].

The main aim of this work is to give insight on the stability and reactivity of AAN under interstellar conditions. We therefore limited our spectra to $\mathrm{hv}<13.6 \mathrm{eV}$. This photon energy domain corresponds to interstellar "HI" regions where atomic hydrogen is not ionized. Photons with higher energies are effectively absorbed by atomic hydrogen in these regions and thus small organic molecules may be protected from rapid destruction. Hence, we studied the single-photon photoionization and dissociative photoionization spectroscopy of gas-phase AAN by means of VUV synchrotron radiation as exciting light source. The interpretation of the experimental spectra was done with the help of quantum chemical calculations. These computations were carried out using both standard ab initio approaches (MP2 and coupled clusters) and the recently implemented explicitly correlated coupled cluster technique (CCSD(T)-F12). For the open-shell species, the partially spin-restricted versions (i.e. RMP2, RCCSD(T), RCCSD(T)-F12) were used instead. Therefore, we characterized the stable forms of the parent and the transition states connecting minimal structures and the corresponding fragmentation pathways. We deduced the ionization energy (IE) of AAN and the appearance energies (AEs) of six fragment ions that could potentially be formed upon dissociative photoionization. In the calculations, numerous isomers have been considered, giving 
strong indications to particular fragmentation pathways.

\section{Methodologies}

\subsection{Experimental details}

The experiments were carried out at the DESIRS beamline of the French synchrotron facility SOLEIL [13] in connection with its $6.65 \mathrm{~m}$ normal incidence monochromator and the photoelectron photoion coincidence (PEPICO) spectrometer DELICIOUS III [14]. Briefly, this spectrometer allows for full momentum detection of ions and velocity map imaging of the electrons at the same time. The direction of ion/electron collection is perpendicular to the molecular beam inlet and to the VUV light propagation direction (all $90^{\circ}$ setup). More details on the experimental operating conditions can be found in ref. [14]. For our measurements, we used the $200 \mathrm{gr} / \mathrm{mm}$ grating of the monochromator with entrance/exit slit widths of typically 100/100 .m yielding a spectral resolution (photons) of $0.72 \AA$ (about $6 \mathrm{meV}$ at $10 \mathrm{eV}$ ).

We collected all photoelectrons having kinetic energies less than $3.5 \mathrm{eV}$ in coincidence with the corresponding photoions. We note here that only when all photoelectrons (slow and fast) are included in the coincidence measurement, the photoionization efficiency (PIE) spectrum (sometimes also called "total ion yield - TIY" spectrum), is proportional to the ionization cross section of the molecule. The determination of useful properties, such as ionization cross sections, is a particular aim of our study. Our PEPICO-PIE spectra are further normalized by the photon flux measured by a photodiode (AXUV, IRD) which is placed after the photoionization region. For better spectral purity, we use the gas filter of the beamline which is filled with 0.25 mbar of Ar. This allows for effective suppression of higher energy stray light of the electron storage ring, as well has higher order radiation of the undulator [15]. The presence of Ar absorption lines in the spectrum arising from this filter allows for calibration of the energy scale to an absolute accuracy of about $1 \mathrm{meV}$.

Synthesis of Aminoacetonitrile. Aminoacetonitrile hydrogensulfate $\left(\mathrm{H}_{2} \mathrm{NCH}_{2} \mathrm{CN} \cdot \mathrm{H}_{2} \mathrm{SO}_{4}\right)$ was purchased from Sigma-Aldrich and used without further purification. In a $250 \mathrm{~mL}$ two-necked flask equipped with a stirring bar and a nitrogen inlet were introduced at room temperature aminoacetonitrile hydrogensulfate $(15.4 \mathrm{~g}, 0.1 \mathrm{~mol})$ and dry dichloromethane $(100 \mathrm{~mL})$. A moderate stream of ammonia was passed through the heterogeneous solution in order to obtain a solution saturated by ammonia after about $30 \mathrm{~min}$. A white solid formed while the mixture reached a temperature of about $35^{\circ} \mathrm{C}$. The mixture was then cooled at room temperature and pentane was added 
$(30 \mathrm{~mL})$ before filtration. The solvent was cautiously removed in vacuo without heating the solution. The aminoacetonitrile was then purified by distillation in vacuo. Yield: $86 \%, 4.8 \mathrm{~g}, 86 \mathrm{mmol}$. The compound can be kept for months at $-20^{\circ} \mathrm{C}$ but turns black and decomposes in few hours at room temperature. ${ }^{1} \mathrm{H}$ NMR $\left(\mathrm{CDCl}_{3}, 400 \mathrm{MHz}\right) \delta 1.53\left(\mathrm{~s}, 2 \mathrm{H}, \mathrm{NH}_{2}\right), 3.36\left(\mathrm{~s}, 2 \mathrm{H}, \mathrm{CH}_{2}\right) .{ }^{13} \mathrm{C} \mathrm{NMR}\left(\mathrm{CDCl}_{3}\right.$, $100 \mathrm{MHz}) \delta 29.7\left({ }^{1} \mathrm{~J}_{\mathrm{CH}}=144.9 \mathrm{~Hz}(\mathrm{t}), \mathrm{CH}_{2}\right), 120.2\left({ }^{2} \mathrm{~J}_{\mathrm{CH}}=7.4 \mathrm{~Hz}(\mathrm{t}), \mathrm{CN}\right)$.

A few $\mathrm{mL}$ of $\mathrm{AAN}$ were warmed up to room temperature and were placed inside the (unheated) oven located a few centimeters upstream the $50 \mu \mathrm{m}$ nozzle/skimmer assembly of the molecular beam chamber of DELICIOUS III. The AAN vapor is expanded with 0.5 bar of He stagnation pressure. The resulting jet cooled molecular beam of AAN/He interacts with the monochromatized VUV light at right angle (see above). Aggregates of AAN are not observed under these conditions.

\subsection{Computational details}

The main aim of these computations is to provide an interpretation of the experimental results. For this purpose we mapped the potential energy surfaces (PESs) of AAN and of its cation AAN ${ }^{+}$. These calculations consist on the optimization of the geometries of the neutral and ionic species. We also calculated their harmonic frequencies to check whether the calculated structures correspond to minima or transition states. The resulting energy profiles include equilibrium geometries, transition states and the lowest cationic fragmentation channels. The calculations were carried out using GAUSSIAN09 (2009 version) [16] and MOLPRO (2012 version) [17]. All molecular structures were fully optimized in the $\mathrm{C}_{1}$ point group. The atoms were described using the aug-cc-pVXZ $(X=D, T, Q)$ basis sets [18].

These computations were performed first at the Möller Plesset [19] (R)MP2 / aug-cc-pVTZ level. Then, the resulting structures were used as starting point for explicitly correlated calculations for better accuracy (see refs. [20a-c]. Indeed, we used the (R)CCSD (T)-F12 method where the atoms were described using the aug-cc-pVXZ $(X=T, D)$ basis sets, in connection with the corresponding auxiliary basis sets and density fitting functions. Here, the default CABS(OptRI) basis sets were used. [21a-d]. We also performed computations using the standard coupled cluster approach with a perturbative treatment of triple excitations $(\mathrm{R}) \operatorname{CCSD}(\mathrm{T})[22 \mathrm{a}, \mathrm{b}]$ in connection with the aug-cc-pVXZ $(\mathrm{X}=\mathrm{T}, \mathrm{Q})[18]$ for comparison. Finally, vertical excitation energies of some fragments were calculated using the state-averaged complete active space self-consistent field (CASSCF) [23] method and the 
aug-cc-pVTZ basis set.

\section{Results and discussion}

\subsection{Time-of-flight mass spectra}

Figure 1 presents the Time-of-flight mass spectra (TOF-MS) of AAN at fixed photon energies from 10 to $13.5 \mathrm{eV}$ with steps of $0.5 \mathrm{eV}$. At $10 \mathrm{eV}$, the TOF-MS shows close to zero signal since this photon energy is below the adiabatic ionization energy (AIE) of AAN in good accordance with Lacombe et al's HeI photoelectron spectrum [11]. These authors observed the threshold for population of the electronic ground state of $\mathrm{AAN}^{+}$at about $10.1 \mathrm{eV}$. Our TOF-MS at $11 \mathrm{eV}$ is dominated by a peak at $m / z, 56$ corresponding to the $\mathrm{AAN}^{+}$parent ion. One can observe also the ${ }^{13} \mathrm{C}$ isotopomer peak of the parent ion, at $\mathrm{m} / \mathrm{z}$ 57. Its weak intensity corresponds well to the terrestrial abundance of ${ }^{13} \mathrm{C}$ (about $2 \%$ of $m / z 56$ ). At higher photon energies, several fragment ions appear, at $m / z 55,30,29$, and 28 (Figure 1). A very weak signal at $m / z, 31$ is also present but not visible in the Figure 1 . The signal at $m / z, 32$ which appears for energies $\geq 12.5 \mathrm{eV}$ is due to photoionization of molecular oxygen present in the residual air in the ionization chamber. We thus observe four different dissociative photoionization reactions in the 10 to $13.5 \mathrm{eV}$ energy regime. The formation of $\mathrm{m} / \mathrm{z} 55$ corresponds to the loss of atomic hydrogen. $\mathrm{m} / \mathrm{z}, 30,29$ and 28 ionic fragments correspond most certainly to the respective loss of $\mathrm{CN}, \mathrm{HCN}$ and $\mathrm{HCNH}$. The weak mass peak at $\mathrm{m} / z, 31$ is due to the loss of $\mathrm{C}_{2} \mathrm{H}$ (or respectively $\mathrm{C}_{2}+\mathrm{H}$, $2 \mathrm{C}+\mathrm{H}, \mathrm{CH}+\mathrm{H})$. This is discussed in section 3.2 .

\subsection{Experimental PEPICO-PIE spectra and quantum chemical calculations}

Figure 2 shows the PEPICO-PIE spectra of $\mathrm{AAN}^{+}(\mathrm{m} / \mathrm{z}, 56)$ and those of the five ionic fragments at $\mathrm{m} / \mathrm{z} 55,31,30,29$ and 28 in the 9.8-13.6 eV photon energy range (step width $4 \mathrm{meV}$ ). Figure 3 displays the respective branching ratios of these reactions as a function of photon energy. As mentioned above, the formation of these ions can be rationalized by loss of $\mathrm{H}, \mathrm{C}_{2} \mathrm{H}, \mathrm{CN}, \mathrm{HCN}$ and $\mathrm{HCNH}$ respectively, from the parent cation (as indicated in figs. 2,3). In order to validate these tentative assignments we have undertaken quantum chemical calculations on the thermochemisty of these dissociation channels (including isomers) and their respective transition states (see below). Figure 4 represents the total ion yield spectrum (TIY, sum of parent and all fragment cation signals). The TIY signal is proportional to the ionization cross section of the molecule which is needed for 
astrochemical modeling. Further work is required for the absolute calibration of this spectrum following, for example, methods outlined in refs. [24,25]. We note however that the measurement of the ionization cross section of unstable molecules that are not gaseous at room temperature is a real experimental challenge that has to be addressed in the future.

Figures 5 presents the calculated optimized structures of the parent species involved as well as transition states (detailed geometry data will be given in a forthcoming publication on AAN [26]). Figure 6 presents the stationary points on the ground state PESs of neutral AAN and cationic AAN ${ }^{+}$. The energies for the different species are given for different levels of theory (see legend of figure 6). For neutral AAN, two minimal structures (denoted as AAN MIN1 and AAN MIN2) are found at all levels of theory. They are separated by a transition state (denoted TS). All of them are of $\mathrm{C}_{\mathrm{s}}$ symmetry. AAN MIN 1 is the most stable form of the neutral molecule. TS and AAN MIN2 are located at 0.13 $\mathrm{eV}$ and $0.07 \mathrm{eV}$ with respect to AAN MIN1, respectively. Because of the jet-cooling, the molecular beam in our experiment should therefore be composed in majority of the AAN MIN1 structured molecule.

\subsubsection{Parent ion at $\mathrm{m} / \mathrm{z}$ 56.}

The experimental ionization energy of aminoacetonitrile is found at $\mathrm{AIE}=(10.085 \pm 0.03) \mathrm{eV}$ as determined from Figure 7a. We assign this threshold to its adiabatic ionization energy. It is difficult to compare this value to the smooth onset seen in the HeI PES from 1989 [11] since the latter study gives nor information about energy resolution neither about absolute accuracy of the energy scale. Furthermore, this HeI spectrum has been taken with room temperature molecules so that the involvement of hot bands or the presence of several rotamers cannot be excluded. We therefore consider our AIE value as the first accurate AIE measurement for this molecule.

Figures 5 and 6 show that the parent cation $\mathrm{AAN}^{+}$possesses a symmetrical potential well where we can find the minimal structure $\mathrm{AAN}^{+}$. Both (equivalent) structures are separated by a potential barrier of $\sim 0.1 \mathrm{eV}$ where a transition state is located $\left(\mathrm{TS}^{+}\right)$. In $\mathrm{AAN}^{+}$, the amine group $\mathrm{NH}_{2}$ and the $\mathrm{C} 1$ atom are co-planar whereas they were pyramidal for neutral AAN. Simple rotation around the C1-N1 bond allows conversion these three ionic structures. All levels of theory lead to AIE(AAN) of $\sim 10 \mathrm{eV}$ in good agreement with the present experimental measurement. The closest theoretical AIE (of 10.01 $\mathrm{eV}$ ) is the one computed at the (R)CCSD(T)-F12/aug-cc-pVDZ level, whereas the standard methods (MP2 and CCSD(T)) show relatively large deviations from the experimental value. This points out 
again the outstanding capabilities of the explicitly correlated coupled clusters approaches for the deduction of accurate energetics for medium sized molecular species, as has been demonstrated before for other molecules (see refs. [10,27,28,29,30]).

The vertical ionization energy of the electronic ground state of $\mathrm{AAN}^{+}$is found at VIE $=$ $10.65 \mathrm{eV}$ from the photoelectron spectrum measured by Lacombe et al. [11]. This compares favorably to the first shoulder observed in our PEPICO-PIE spectrum. The rich structure seen in the PEPICO-PIE spectrum of the parent cation (cf. fig. 2) is currently under investigation. According to [11], at least 3 ionic states are involved in the energy regime from the IE up to $13.6 \mathrm{eV}$. A detailed analysis of the bands observed in the $\mathrm{m} / \mathrm{z} 56$ PEPICO-PIE spectrum will be presented later [26], also using the method of Slow Photoelectron Spectroscopy (SPES [31]) which gives insights into the ionizing mechanisms.

\subsubsection{Fragment at $\mathrm{m} / \mathrm{z} 55$}

As can be seen from figures $1-3, \mathrm{~m} / \mathrm{z} 55$ is the strongest ion at $13.6 \mathrm{eV}$ which is the highest excitation energy we investigated. The threshold region of the PEPICO-PIE curve of $\mathrm{m} / z 55$ is shown in figure $7 \mathrm{~b}$. The experimental appearance energy is determined to be $\mathrm{AE}_{\text {exp }}=(11.17 \pm 0.03) \mathrm{eV}$. We assign this mass to the ion formed by $\mathrm{H}$ loss reaction from the parent cation. We have investigated theoretically, at the (R)MP2/aug-cc-pVTZ level, the formation of seven possible polyatomic ions in connection with the $\mathrm{H}$ loss reaction. The corresponding results are given in Table 1. As can be seen there, the observed experimental appearance energy deduced from our PEPICO-PIE spectrum corresponds remarkably well to the $\mathrm{AE}$ that is calculated for rupture of one of the two (equivalent) $\mathrm{C} 1-\mathrm{H}$ bonds (cf. figure 5 for atom numbering). The removal of an $\mathrm{H}$ from the $\mathrm{N} 1$ atom leads to rearrangements of the resulting cation, with appearance energies significantly higher than the observed experimental threshold (cf. Table 1). At present we do not, however, exclude the contribution of even other isomeric forms of the [AAN-H] $]^{+}$species to $\mathrm{m} / z 55$ in our spectra, especially at higher energies. In fact, the observed steps in the PEPICO-PIE spectrum of $\mathrm{m} / \mathrm{z} 55$ could, in principle, be associated with the opening-up of new fragmentation channels forming other isomers. But they could also correspond to a gradual increase in the absorption cross section $\sigma_{\text {abs }}$ (unknown up to now for AAN). In figure 2, one can observe pronounced steps at about 12.1 and $13.2 \mathrm{eV}$ for all ionic fragments. At these energies, the $1^{\text {st }}$ and the $2^{\text {nd }}$ excited state of $\mathrm{AAN}^{+}$begin to get populated as can be seen from ref. [11]. Since these two steps are observed for all fragments, an increase in the absorption is probably occurring at these energies. However, this has to be 
clarified in future work [26].

\subsubsection{Fragment at $\mathrm{m} / \mathrm{z}, 30$}

The appearance energy of the intense fragment ion $\mathrm{m} / \mathrm{z} 30$ has been measured to be $\mathrm{AE}_{\exp }=$ $(10.93 \pm 0.03) \mathrm{eV}$ (see arrow figure 7c). The formation of this fragment ion corresponds to the loss of a $\mathrm{CN}$ radical from the $\mathrm{AAN}^{+}$parent. This is confirmed by the present computations as shown in table $2 \mathrm{a}$. Indeed, the computed appearance energy for this fragment is $\sim 11.2 \mathrm{eV}$ at all levels of theory except (R)CCSD(T)-F12/aug-cc-pVTZ which lies closest to $\mathrm{AE}_{\exp }$, at $\mathrm{AE}_{\text {calc }}=10.88 \mathrm{eV}$. These theoretical results are thus consistent with the measured value. Moreover, the spectrum shows an increase of the signal at $\sim 12.2 \mathrm{eV}$ (cf. fig. 2), which is close to the $11.90 \mathrm{eV}$ appearance energy computed at the (R)MP2/aug-cc-pVTZ level and associated with the formation of the ionic fragment in its electronic excited state (result not shown in table $2 \mathrm{a})$. Therefore, the low energy part $(<11.9 \mathrm{eV})$ of the spectrum of Figure 2 is attributed to the AAN $(\mathrm{X})+\mathrm{h} v \rightarrow \mathrm{H}_{2} \mathrm{NCH}_{2}^{+}(\mathrm{X})+\mathrm{CN}(\mathrm{X})$. At energies exceeding $\mathrm{E}=$ $11.9 \mathrm{eV}$, the AAN $(\mathrm{X})+\mathrm{h} v \rightarrow \mathrm{H}_{2} \mathrm{NCH}_{2}^{+}(\mathrm{A})+\mathrm{CN}(\mathrm{X})$ dissociation probably occurs.

\subsubsection{Fragment at $\mathrm{m} / \mathrm{z}, 29$}

The appearance energy of the intense fragment ion $\mathrm{m} / \mathrm{z} 29$ has been measured to be $\mathrm{AE}_{\exp }=$ $(11.07 \pm 0.03) \mathrm{eV}$ (see arrow figure $7 \mathrm{~d}$ ). This fragmentation pathway corresponds to the loss of neutral $\mathrm{HCN}$ or $\mathrm{HNC}$ forming thereby an ion with the elemental formula $\mathrm{CH}_{3} \mathrm{~N}^{+}$. In figure 2, several signal onsets can be seen in the PEPICO-PIE spectrum of $\mathrm{m} / \mathrm{z}$ 29. Table $2 \mathrm{a}$, which summarizes the main theoretical results we obtained for the intense ions, shows that in the energy regime under investigation here, the possible fragmentation pathways yielding $\mathrm{m} / \mathrm{z} 29$ include two isomeric forms of $\mathrm{CH}_{3} \mathrm{~N}^{+}$ $\left(\mathrm{HNCH}_{2}{ }^{+}\right.$and $\left.\mathrm{HCNH}_{2}^{+}\right)$as well as formation of $\mathrm{HCN}$ or $\mathrm{HNC}$. The branching ratios of these four channels could however vary which remains to be investigated in connection with calculations on the structure and energy of the involved transition states. The measured appearance energy of $\mathrm{m} / z, 29$ compares most favorably to the formation of neutral $\mathrm{HCN}$ and $\mathrm{HCNH}_{2}^{+}$(cf. table 2a). For the photon energy regime beyond $13.6 \mathrm{eV}$, our calculations show that additional fragmentation pathways lead to the formation of excited states of the $\mathrm{HCNH}_{2}{ }^{+}$or $\mathrm{HNCH}_{2}{ }^{+}$fragment (at $\mathrm{E}>15 \mathrm{eV}$ ). These pathways can include HCN and HNC as neutral fragments (see Table 2a for more details).

\subsubsection{Weaker ions}

$\mathrm{m} / \mathrm{z}$ 31. This ion is hardly visible in the TOF-MS shown in figure 1 , however it can been seen 
upon zooming in the baseline. Its $\mathrm{AE}$ is determined experimentally to be $\mathrm{AE}_{\mathrm{exp}}=(10.95 \pm 0.05) \mathrm{eV}$ (cf. fig. 2). The formation of this ion is by loss of a species of elemental formula $\mathrm{C}_{2} \mathrm{H}$. Given its minor importance, no quantum chemical calculations have been performed to explain the formation of this ion.

$m / z$ 28. This ion is also hardly visible in the TOF-MS shown in figure 1 , however it can be seen upon zooming in the baseline. Its $\mathrm{AE}$ is determined experimentally to be $\mathrm{AE}_{\mathrm{exp}}=(11.1 \pm 0.05) \mathrm{eV}$ (cf. fig. 2). The $m / z, 28$ ion has the elemental formula $\mathrm{CH}_{2} \mathrm{~N}^{+}$. The corresponding neutral that is produced in the dissociation reaction has the same elemental formula. We note that $\mathrm{HCNH}^{+}$(protonated hydrogen cyanide) and $\mathrm{H}_{2} \mathrm{CN}$ (methylene amidogen) are molecules of astrophysical interest and have both been observed in interstellar space (see for example ref. [32]). Therefore, we have undertaken theoretical calculations in order to investigate the possible formation of these two species in the dissociative photoionization of AAN. The results show that indeed, $\mathrm{HCNH}^{+}$and $\mathrm{H}_{2} \mathrm{CN}$ can be formed below 13.6 eV upon photoionization of AAN (see left column of table 2b). The formation of these two species is associated to the lowest calculated appearance energy, which is furthermore in good accordance with the measurement of $\mathrm{AE}_{\text {exp }}$. Other neutral $\mathrm{CH}_{2} \mathrm{~N}$ isomers are formed too, however always in combination with $\mathrm{HCNH}^{+}$. According the calculations, four different ionic dissociation channels could potentially occur in a relatively small interval between the IE and IE $+1.2 \mathrm{eV}$ approximately. At higher excitation energies $(>14 \mathrm{eV})$, the cation that is formed is an isomer with $\mathrm{CNH}_{2}{ }^{+}$structure according to the calculations (see right column of table $2 \mathrm{~b}$ ).

$m / z 27$ and $m / z 26$. These two ions are not seen in our mass spectra. This is reasonable since their formation thresholds lie beyond the energy regime of our study according to the calculations presented in Table $2 \mathrm{~b}$.

\section{Concluding comments and astrophysical implications}

We have presented a combined theoretical and experimental study dealing with the photoionization and dissociative photoionization of aminoacetonitrile in the gas phase. Accurate thermochemical data, to our knowledge all of them for the first time, were deduced. The interpretation and assignment of the experimental findings requires state-to-the-art theoretical methodologies. In this context, the newly implemented explicitly correlated methods are viewed to provide accurate data with reduced computational cost [33]. 
The adiabatic IE of AAN is found at $\mathrm{AIE}=(10.085 \pm 0.03) \mathrm{eV}$. Our results show that AAN can form a parent ion which is stable up to approximately $\mathrm{IE}+1 \mathrm{eV}$. Starting at $\sim 11 \mathrm{eV}$, numerous fragments will be formed, among them astrophysically important species like CN, HCN, HNC, $\mathrm{HCNH}^{+}$and $\mathrm{H}_{2} \mathrm{CN}$. This reduces significantly the partial quantum yield of $\mathrm{AAN}^{+}$, to about $18 \%$ at 13.6 eV. It is furthermore remarkable that the five different ionic fragmentation pathways observed below $13.6 \mathrm{eV}$ all have their thresholds in the small interval of $(11.1 \pm 0.1) \mathrm{eV}$. We are currently investigating the possible existence of common transition state or intermediate structure of these pathways. The observed threshold energy interval of $\mathrm{E}=(11.1 \pm 0.1) \mathrm{eV}$ lies between two ionic states of $\mathrm{AAN}^{+}$so that a significant increase of $\sigma_{\mathrm{abs}}$ is à priori not expected at this energy. We will measure the absorption spectrum of AAN in future work in order to further address this question.

From a perspective point of view, our work shows that photoion and photoelectron spectra of organic medium sized molecules may have different contributions associated with different photoionization and dissociative ionization processes, which are worth to investigate by means of the emerging photoelectron spectroscopies such as slow photoelectron spectroscopy (see for example ref. [31]).

The present findings should be incorporated into astrochemistry models dedicated to the physico-chemical characterization of objects in the ISM, cometary or planetary atmospheres. For this purpose, we have displayed in this article the total ion yield spectrum of AAN that can be calibrated later to photoionization cross section with a measurement at one specific energy. We note that the measurement of absolute photoionization cross sections for unstable compounds that are not gaseous at room temperature is still an experimental challenge. Furthermore, this quantity cannot be calculated at present. We have also displayed branching ratios of the five ions that can be formed by dissociative photoionization in the 10 to $13.6 \mathrm{eV}$ energy regime.

\section{Acknowledgments}

This study was undertaken while M.H. was a Visiting Professor at King Saud University. The support of the Visiting Professor Program at King Saud University is hereby gratefully acknowledged. We are indebted to the general technical staff of Synchrotron Soleil for the running the facility. We would like also to thank Gustavo A. Garcia, Laurent Nahon and Jean-François Gil for the excellent support during measurements. We acknowledge financial support from the French National Program Physique et 
Chimie $d u$ Milieu Interstellaire, PCMI (INSU, CNRS) and the $7^{\text {th }}$ European Community Framework Program under COST ACTION CM1405 MOLIM. 


\section{References}

[1] E. Herbst, E.F. van Dishoeck, EF, Annu. Rev. Astron. Astrophys. 47 (2009) 427-480.

[2] A. Belloche, H.S.P. Müller, K.M. Menten, P. Schilke, C. Comito, Astron. Astrophys. 559 (2013), A47.

[3] J.M. Hollis, F.J. Lovas A.J. Remijan P.R. Jewell V.V. Ilyushin I. Kleiner, Astrophys. J. 643 (2006) L25-L28.

[4] A. Belloche K.M. Menten C. Comito C, H.S.P. Müller P. Schilke, J. Ott J, S. Thorwirth C. Hieret, Astron. Astrophys. 482 (2008)179-196.

[5] (a) A. Strecker, Ann. Chem. Pharm. 75 (1850) 27-45; (b) A. Strecker, Ann. Chem. Pharm. 91 (1854) 349-351.

[6] J.E. Elsila, J.P. Dworkin, M.P. Bernstein, M.P. Martin, S.A. Sandford, Astrophys. J. 660 (2007) 911-918.

[7] U. Meierhenrich (2008) Amino acids and the Asymmetry of Life. Advances in Astrobiology and Biogeophysics, Springer, Berlin Heidelberg.

[8] D.M. Koch, C. Toubin, G.H. Peslherbe, J.T. Hynes, J. Phys. Chem. C 112 (2008) 2972-2980.

[9] G. Danger, F. Borget, M. Chomat, F. Duvernay, P. Theulé, J.C. Guillemin, L. Le Sergeant d'Hendecourt, T. Chiavassa, Astron. Astrophys. 535 (2011) A47:1-9.

[10] A. Bellili, M. Schwell, Y. Bénilan, N. Fray, M.-C. Gazeau, M. Mogren Al-Mogren, J.C. Guillemin, L. Poisson, M. Hochlaf, J. Chem Phys. 141 (2014) 134311.

[11] S. Lacombe, B. Pellerin, J.C. Guillemin, J.M. Denis, G. Pfister-Guillouzo, J. Org. Chem. 54 (1989) 5958-5963.

[12] M. Nagnathappa, A. Chaudhari, Int. J. Quantum Chem. 111 (2009) 2065.

[13] L. Nahon, N. de Oliveira N, G.A. Garcia, J.F. Gil, B. Pilette, O. Marcouillé, B. Lagarde, F. Polack, J. Synchrotron Radiat. 19 (2012) 508-520.

[14] G.A. Garcia, B.K. Cunha de Miranda, M. Tia, S. Daly, L. Nahon, Rev. Sci. Instr. 85 (2013) 053112.

[15] B. Mercier, M. Compin, C. Prevost, G. Bellec, R. Thissen, O. Dutuit, L. Nahon, J. Vac. Sci. Technol. A 18 (2000) 2533-2541.

[16] Gaussian 09, Revision A.02, Frisch, M. J.; Trucks, G. W.; Schlegel, H. B.; Scuseria, G. E.; Robb, M. A.; Cheeseman, J. R.; Scalmani, G.; Barone, V.; Mennucci, B.; Petersson, G. A.; Nakatsuji, H.; Caricato, M.; Li, X.; Hratchian, H. P.; Izmaylov, A. F.; Bloino, J.; Zheng, G.; Sonnenberg, J. L.; Hada, M.; Ehara, M.; Toyota, K.; Fukuda, R.; Hasegawa, J.; Ishida, M.; Nakajima, T.; Honda, Y.; Kitao, O.; Nakai, H.; Vreven, T.; Montgomery, Jr., J. A.; Peralta, J. E.; Ogliaro, F.; Bearpark, M.; Heyd, J. J.; Brothers, E.; Kudin, K. N.; Staroverov, V. N.; Kobayashi, R.; Normand, J.; Raghavachari, K.; Rendell, A.; Burant, J. C.; Iyengar, S. S.; Tomasi, J.; Cossi, M.; Rega, N.; Millam, N. J.; Klene, M.; Knox, J. E.; Cross, J. B.; Bakken, V.; Adamo, C.; Jaramillo, J.; Gomperts, R.; Stratmann, R. E.; Yazyev, O.; Austin, A. J.; Cammi, R.; Pomelli, C.; Ochterski, J. W.; Martin, R. L.; Morokuma, K.; Zakrzewski, V. G.; Voth, G. A.; Salvador, P.; Dannenberg, J. J.; Dapprich, S.; Daniels, A. D.; Farkas, Ö.; Foresman, J. B.; Ortiz, J. V.; Cioslowski, J.; Fox, D. J. Gaussian, Inc., Wallingford CT, 2009.

[17] Werner, H.-J.; Knowles, P. J.; Knizia, G.; Manby, F. R.; Schütz, M.; Celani, P.; Korona, T.; Lindh, R.; Mitrushenkov, A.; Rauhut, G.; Shamasundar, K. R.; Adler, T. B.; Amos, R. D.; Bernhardsson, A.; Berning, A.; Cooper, D. L.; Deegan, M. J. O.; Dobbyn, A. J.; Eckert, F.; Goll, E.; Hampel, C.; Hesselmann, A.; Hetzer, G.; Hrenar, T.; Jansen, G.; Köppl, C.; Liu, Y.; Lloyd, A. W.; Mata, R. A.; 
May, A. J.; McNicholas, S. J.; Meyer, W.; Mura, M. E.; Nicklass, A.; O’Neill, D. P.; Palmieri, P.; Peng, D.; Pflüger, K.; Pitzer, R.; Reiher, M.; Shiozaki, T.; Stoll, H.; Stone, A. J.; Tarroni, R.; Thorsteinsson, T.; and Wang, M. MOLPRO is a package of ab initio programs, see http://www.molpro.net.

[18] (a) T.H. Dunning, J. Chem. Phys. 90 (1989) 1007. (b) R.A. Kendall, T.H. Dunning, R.J. Harrison. J. Chem. Phys. 96 (1992) 6796.

[19] C. Møller and M.S. Plesset, Phys. Rev. 46 (1934) 618.

[20] (a) T.B. Adler, G. Knizia, H.J. Werner, J. Chem. Phys. 127 (2007) 221106. (b) H.J. Werner, G. Knizia, F.R. Manby, Mol. Phys. 109 (2011) 407; (c) G. Knizia, T.B. Adler H.J. Werner, J. Chem. Phys. 130 (2009) 054104.

[21] (a) F. Weigend. Phys. Chem. Chem. Phys. 4 (2002) 4285; (b) C. Hättig, Phys. Chem. Chem. Phys. 7 (2005) 59; (c) W. Klopper, Mol. Phys. 99 (2001) 481. (d) K.E. Yousaf, K.A. Peterson, J. Chem. Phys. 129 (2008) 184108.

[22] (a) G.D. Purvis III, R.J. Bartlett, J. Chem. Phys. 76 (1982) 1910; (b) C. Hampel, K.A. Peterson, H.J. Werner, Chem. Phys. Lett. 190 (1992) 1.

[23] (a) P.J. Knowles, H.J. Werner, Chem. Phys. Lett. 115 (1985) 259; (b) H.J. Werner P.J. Knowles, J. Chem. Phys. 82 (1985) 5053.

[24] K. Kameta, N.Kouchi, M. Ukai, Y. Hatano, J. Electron Spectrosc. Relat. Phenom. 123 (2002) 225 -238 .

[25] T.A. Cool, J. Wuang, K. Nakajima, C.A. Taatjes, A. Mcllroy, Int. J. Mass Spectrom. 247 (2005), 18.

[26] A. Bellili, M. Schwell, Y. Bénilan, N. Fray, M.-C. Gazeau, M. Mogren Al-Mogren, J.C. Guillemin, L. Poisson, M. Hochlaf, manuscript in preparation.

[27] Y. Pan, K.C. Lau, L. Poisson, G.A. Garcia, L. Nahon, M. Hochlaf, J. Phys. Chem. A 117 (2013) 8095

[28] M. Schwell, M. Hochlaf, Top. Curr. Chem. 355 (2015) 155-208

[29] Y. Majdi, M. Hochlaf, Y. Pan, K.-C. Lau, L. Poisson, G. A. Garcia, L. Nahon, M. Mogren Al Mogren, M. Schwell. J. Phys. Chem. A (2014), in press (to be updated in the accepted version of this paper).

[30] M. Hochlaf, Y. Pan, K.-C. Lau, Y. Majdi, L. Poisson, G. A. Garcia, L. Nahon, M. Mogren Al Mogren and M. Schwell, under review (to be updated in the accepted version of this paper).

[31] (a) J.C. Poully, J.P. Schermann, N. Nieuwjaer, F. Lecomte, G. Gregoire, C. Desfrancois, G.A. Garcia, L. Nahon, D. Nandi, L. Poisson, M. Hochlaf, Phys. Chem. Chem. Phys. 12 (2010) 3566-3572. (b) M. Briant, L. Poisson, M. Hochlaf, P. de Pujo, M.-A. Gaveau, B. Soep, Phys. Rev. Lett. 109 (2012) 193401.

[32] The Cologne Database for Molecular Spectroscopy (www.astro.uni-koeln.de/cdms).

[33] (a) V. Brites and M. Hochlaf. J. Phys. Chem. A 113 (2009) 11107; (b) H.J. Werner, G. Knizia, T.B. Adler, O. Marchetti, Z. Phys. Chem. 224 (2010) 493. 
VUV photoionization and dissociative photoionization of the interstellar molecule aminoacetonitrile: theory and experiment

Ayad Bellili et al.

7 Figures with associated captions

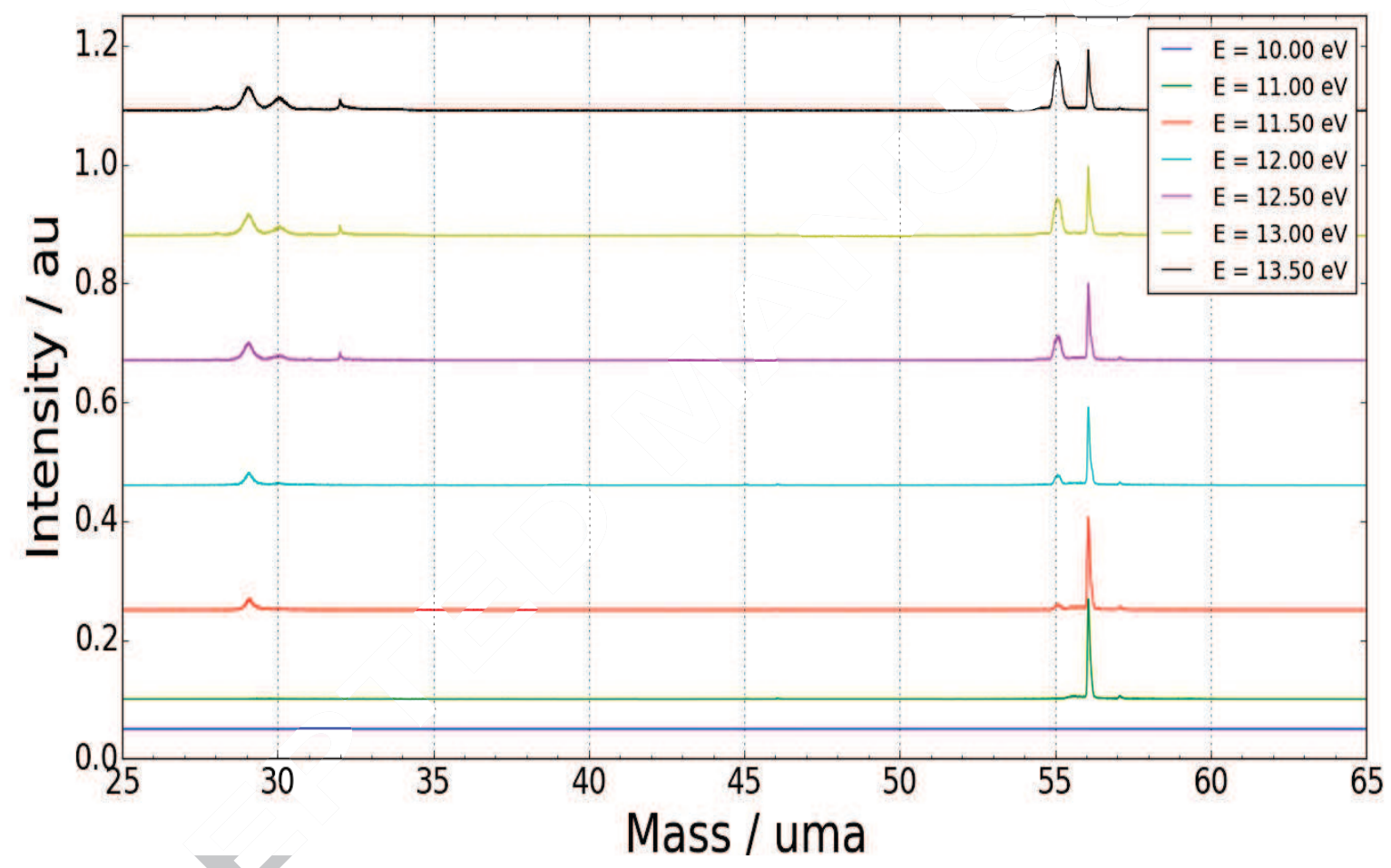

Figure 1: Time-of-flight mass spectra of aminoacetonitrile recorded between 10 and $13.5 \mathrm{eV}$ photon energies $(0.5 \mathrm{eV}$ step width). The range of the $\mathrm{Y}$ axis is the same for all spectra. 


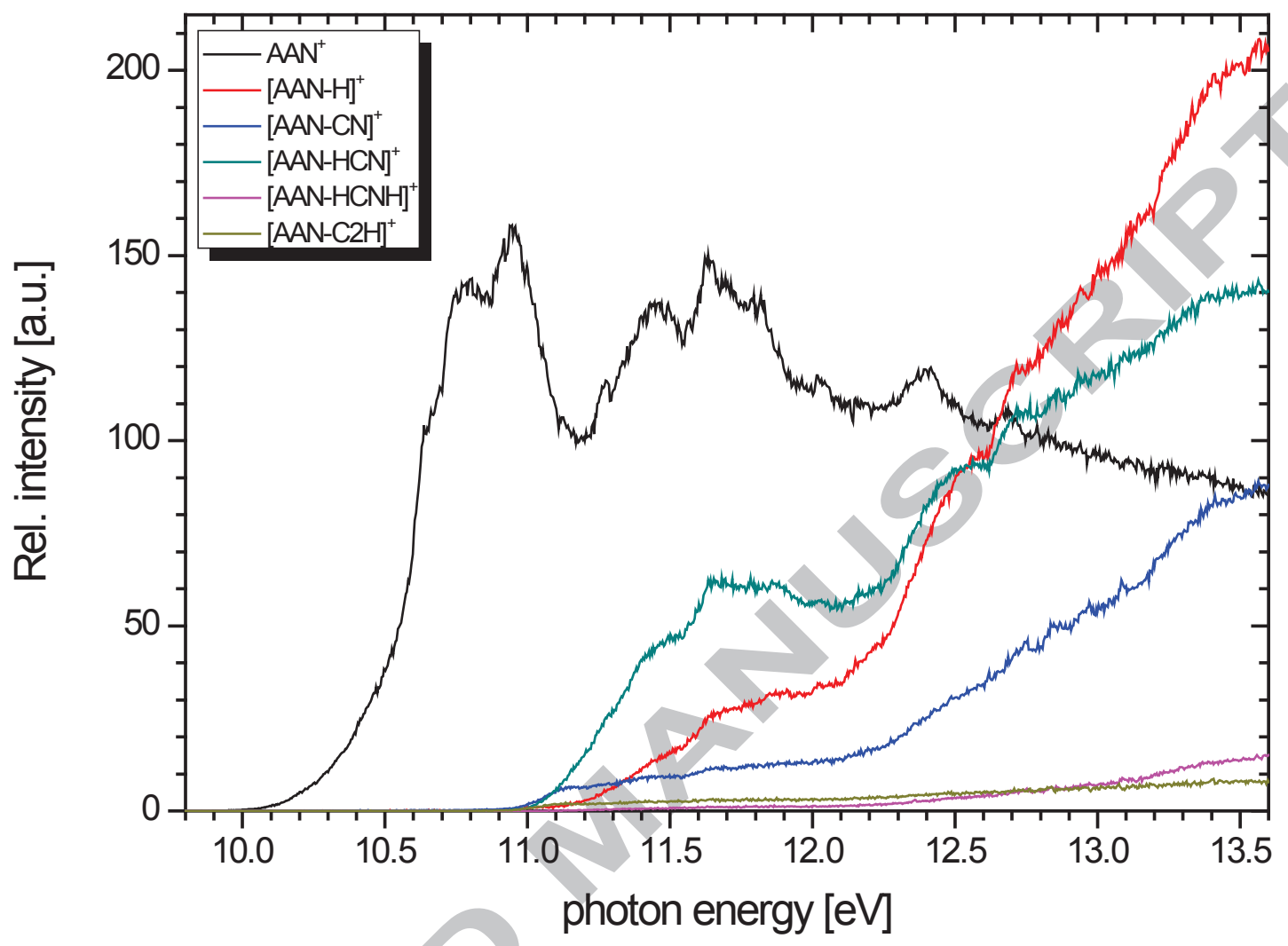

Figure 2: PEPICO-PIE spectra as a function of the photon energy in the 9.8-13.6 eV range for $m / z 56$ $\left(\mathrm{AAN}^{+} \text {; black line), } m / z 55 \text { ([AAN-H] }\right]^{+}$; red line), m/z 30 ([AAN-CN] $]^{+}$; blue line), $m / z 29$ ([AAN$\mathrm{HCN}]^{+}$; dark cyan), $m / z 28$ ([AAN-HCNH] $]^{+}$; magenta) and $m / z 31$ ([AAN-C2H] $]^{+}$; dark yellow). 


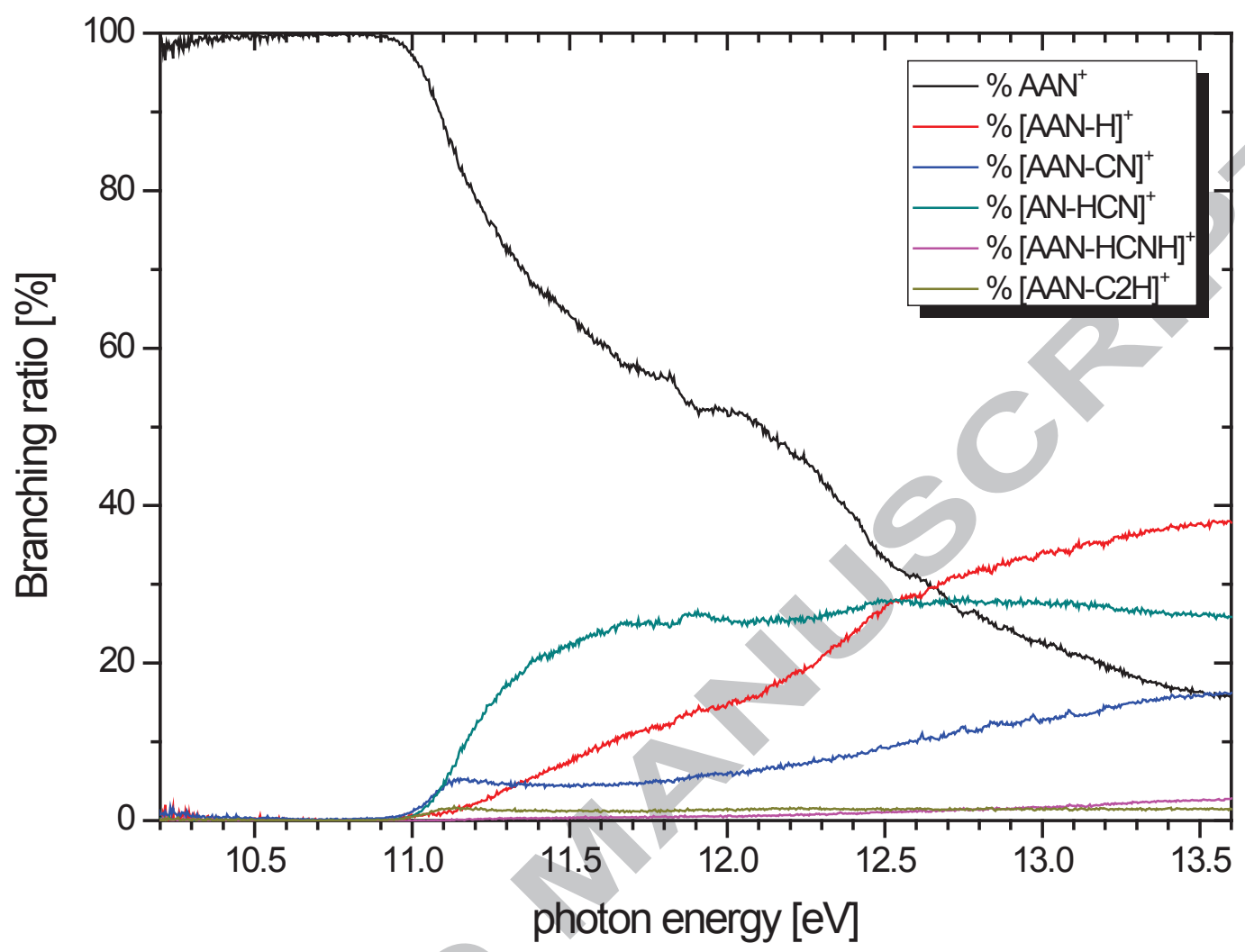

Figure 3: Branching ratios of 5 different dissociative ionization reactions as deduced from PEPICOPIE spectra (color code is the same as in figure 2). 


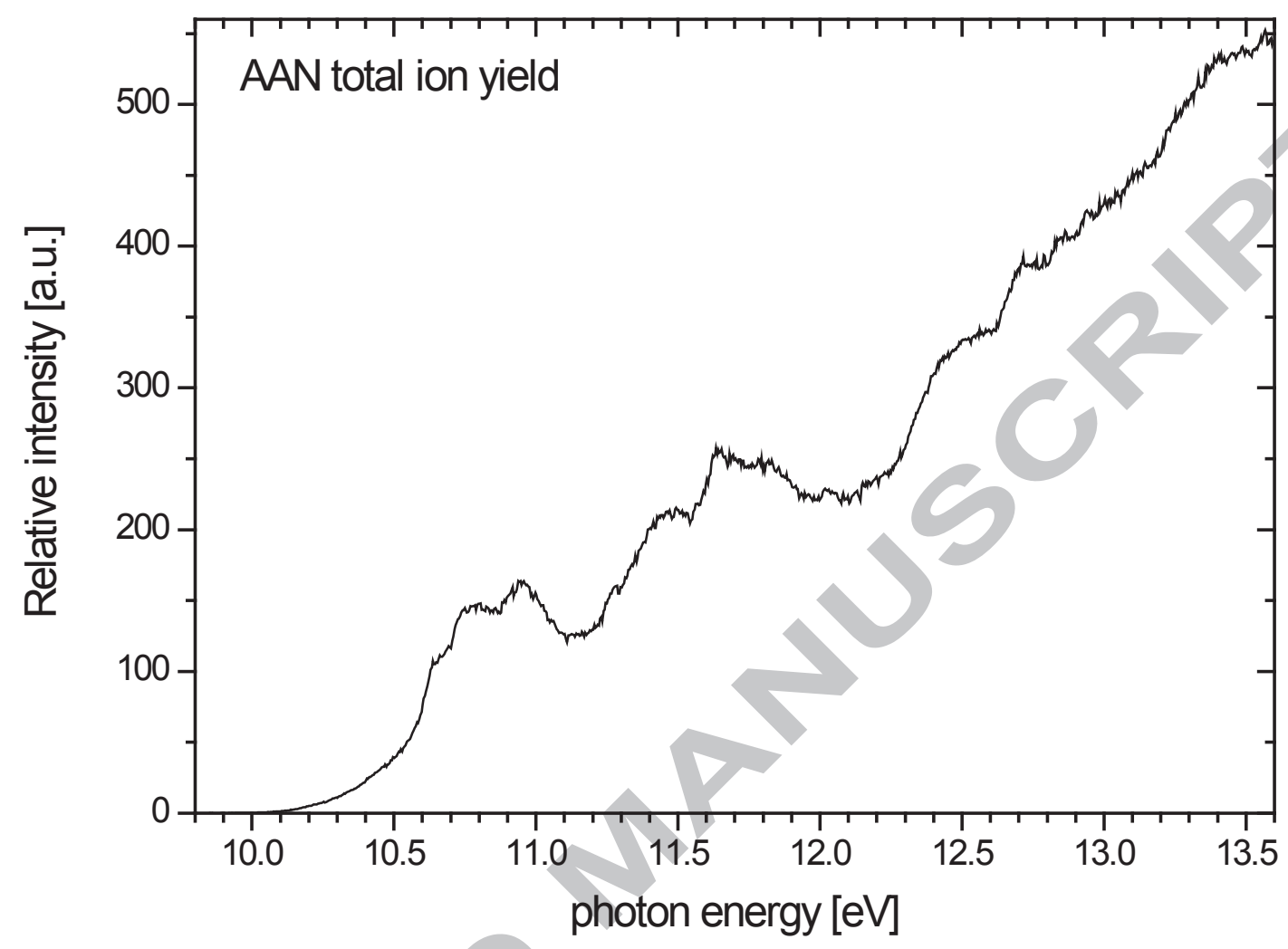

Figure 4: Total ion yield of aminoacetonitrile as determined from PEPICO-PIE spectra (sum of all ions including parent cation). 


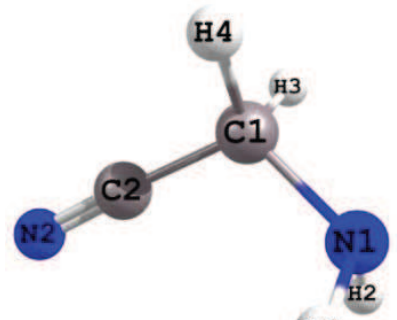

H1

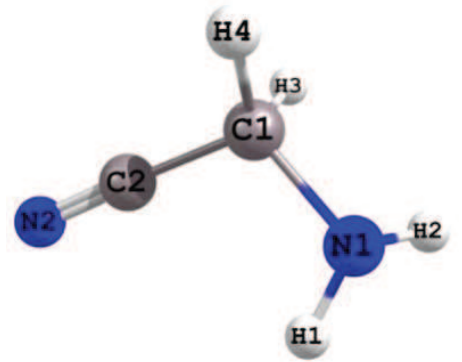

TS

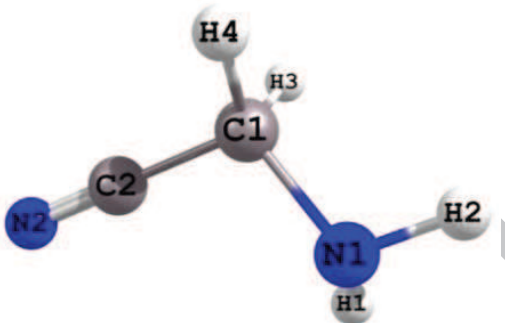

AAN MIN2
AAN MIN1

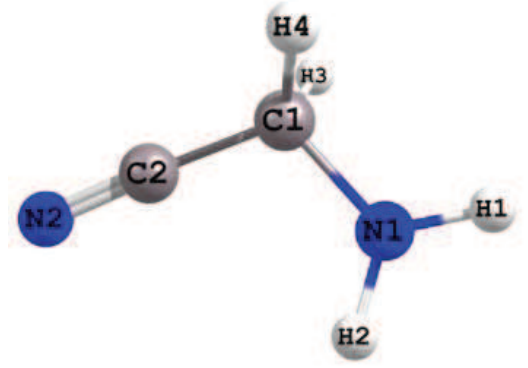

AAN $^{+}$

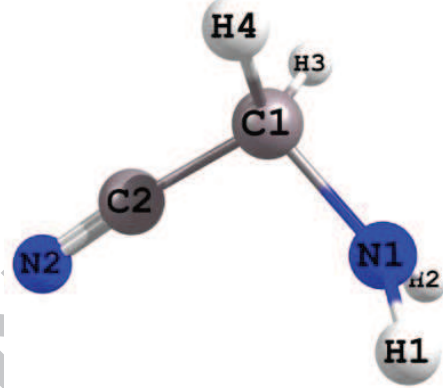

TS $^{+}$

Figure 5: Optimized structures of neutral and cationic aminoacetonitrile species in their electronic ground states. 

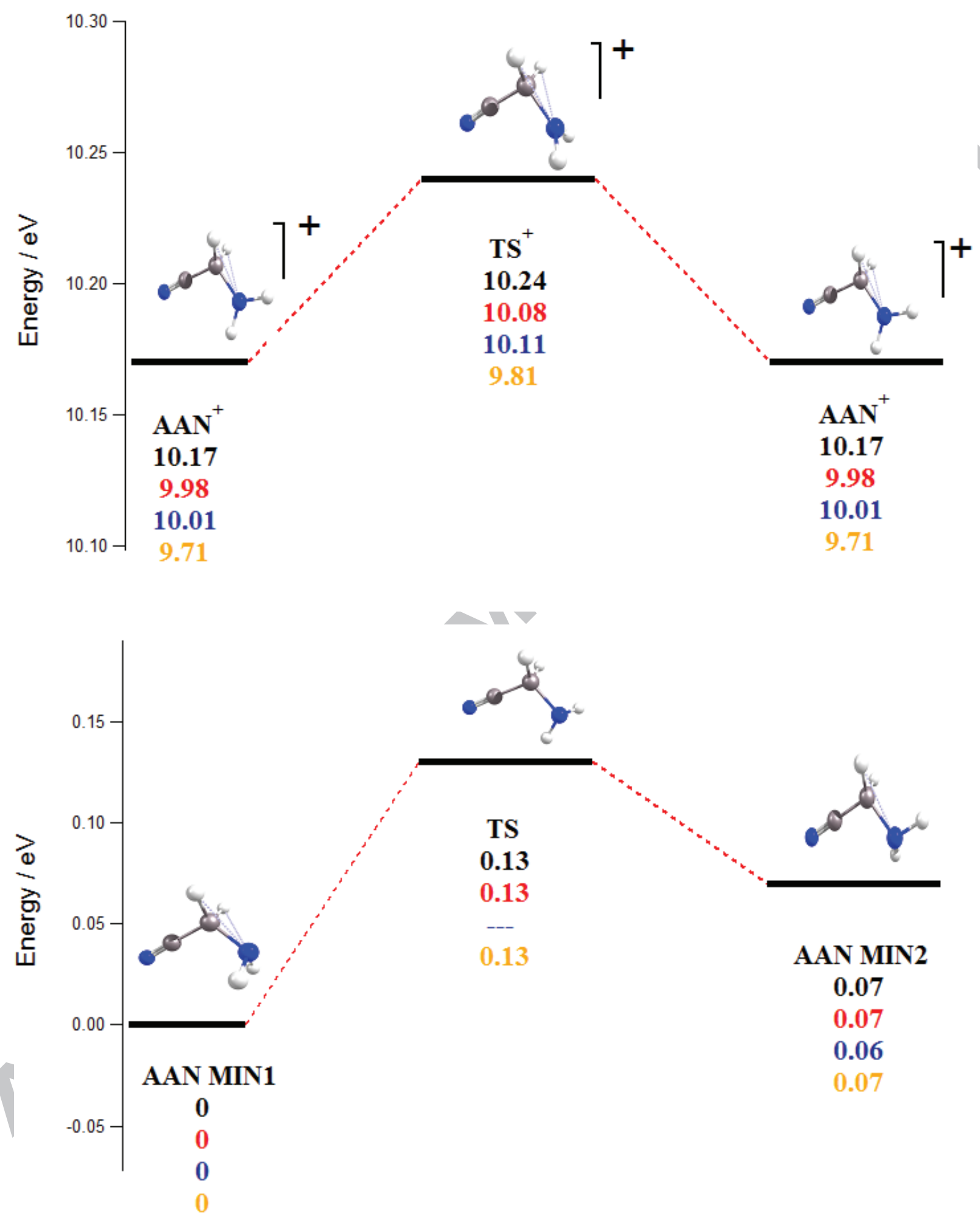

Figure 6: Stationary points of ground state potential energy surfaces (PESs) of AAN and of $\mathrm{AAN}^{+}$. The calculated energies are given with respect to neutral AAN MIN1 ground state. The level of theory is indicated by the following color code: (R)MP2/aug-cc-pVTZ (Opt) (black), (R)CCSD(T)/aug-cc-pVTZ (Opt) (red), (R)CCSD(T)-F12/aug-cc-pVDZ (Opt) (blue), (R)CCSD(T)-F12/aug-cc-pVTZ (Opt) (yellow). Opt means for full geometry optimizations. 

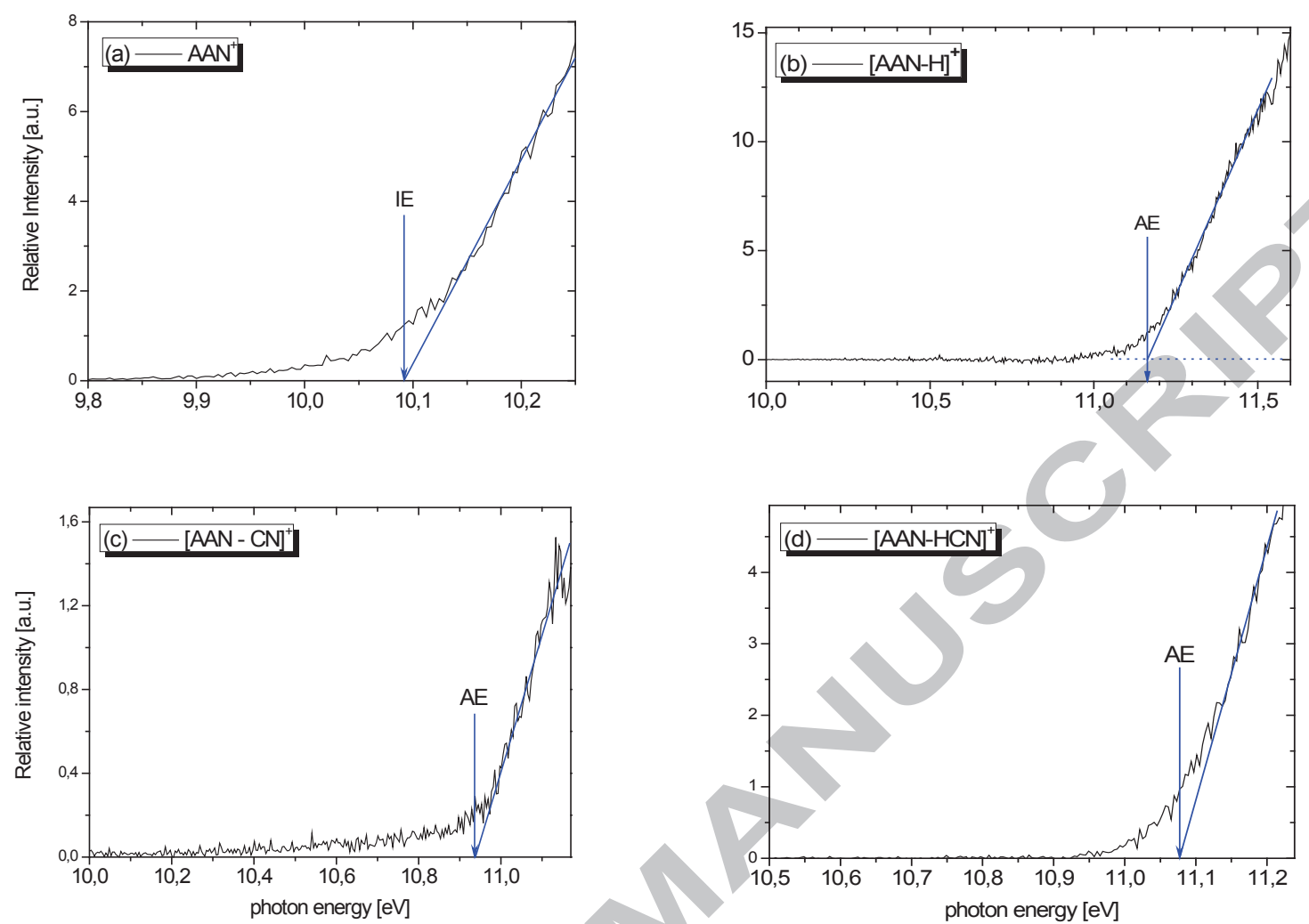

Figure 7: Threshold regions of PEPICO-PIE spectra the 4 major ions and graphic determination of their appearance energies. (a) parent ion $m / z 56\left(\mathrm{AAN}^{+}\right)$, (b) $m / z 55$ ([AAN-H] $\left.]^{+}\right)$, (c) $m / z 30$ ([AAN$\left.\mathrm{CN}]^{+}\right),(\mathrm{d}) m / z 29\left([\mathrm{AAN}-\mathrm{HCN}]^{+}\right)$. 
VUV photoionization and dissociative photoionization of the interstellar molecule aminoacetonitrile: theory and experiment

Ayad Bellili et al.

2 Tables 
Table 1. Computed appearance energies $(\mathrm{AE})$ of different isomeric $[\mathrm{AAN}-\mathrm{H}]^{+}$fragments $(\mathrm{m} / \mathrm{z}=55)$. These energies were calculated at the (R)MP2/aug-cc-pVTZ level. The experimental value is $\mathrm{AE}_{\exp }=$ $(11.17 \pm 0.03) \mathrm{eV}$ (this work).

\begin{tabular}{|c|c|c|}
\hline $\begin{array}{c}\text { Dissociation } \\
\text { channel }\end{array}$ & $\begin{array}{c}{[\mathrm{AAN}-\mathrm{H}]^{+} \text {isomer }} \\
\text { structure }\end{array}$ & $\mathrm{AE}_{\text {calc }}[\mathrm{eV}]$ \\
\hline $\mathrm{NH}_{2} \mathrm{CHCN}^{+}+\mathrm{H}$ & & \\
\hline $\mathrm{NCCNH}_{3}^{+}+\mathrm{H}$ & & \\
\hline $\mathrm{NHCCNH}_{2}^{+}+\mathrm{H}$ & & \\
\hline $\mathrm{H}_{2} \mathrm{NCCNH}^{+}+\mathrm{H}$ & & \\
\hline
\end{tabular}


Table 2a: Experimental appearance energies $\left(\mathrm{AE}_{\exp }\right)$ of fragment ions with strong intensity observed in the dissociative photoionization of $\mathrm{AAN}$. Calculated appearance $\mathrm{AE}_{\mathrm{cal}}$, using five different methods, are given for different fragmentation pathways (on top of the reaction arrow). The theoretical method is given as a color code: (R)MP2/aug-cc-pVTZ (Opt) (black), (R)CCSD(T)/aug-cc-pVTZ (Opt) (red), (R)CCSD(T)/aug-cc-pVQZ (Opt) (green), (R)CCSD(T)-F12/aug-cc-pVDZ (Opt) (blue), (R)CCSD(T)-F12/aug-cc-pVTZ (Opt) (yellow). Opt is for full geometry optimizations (see text).

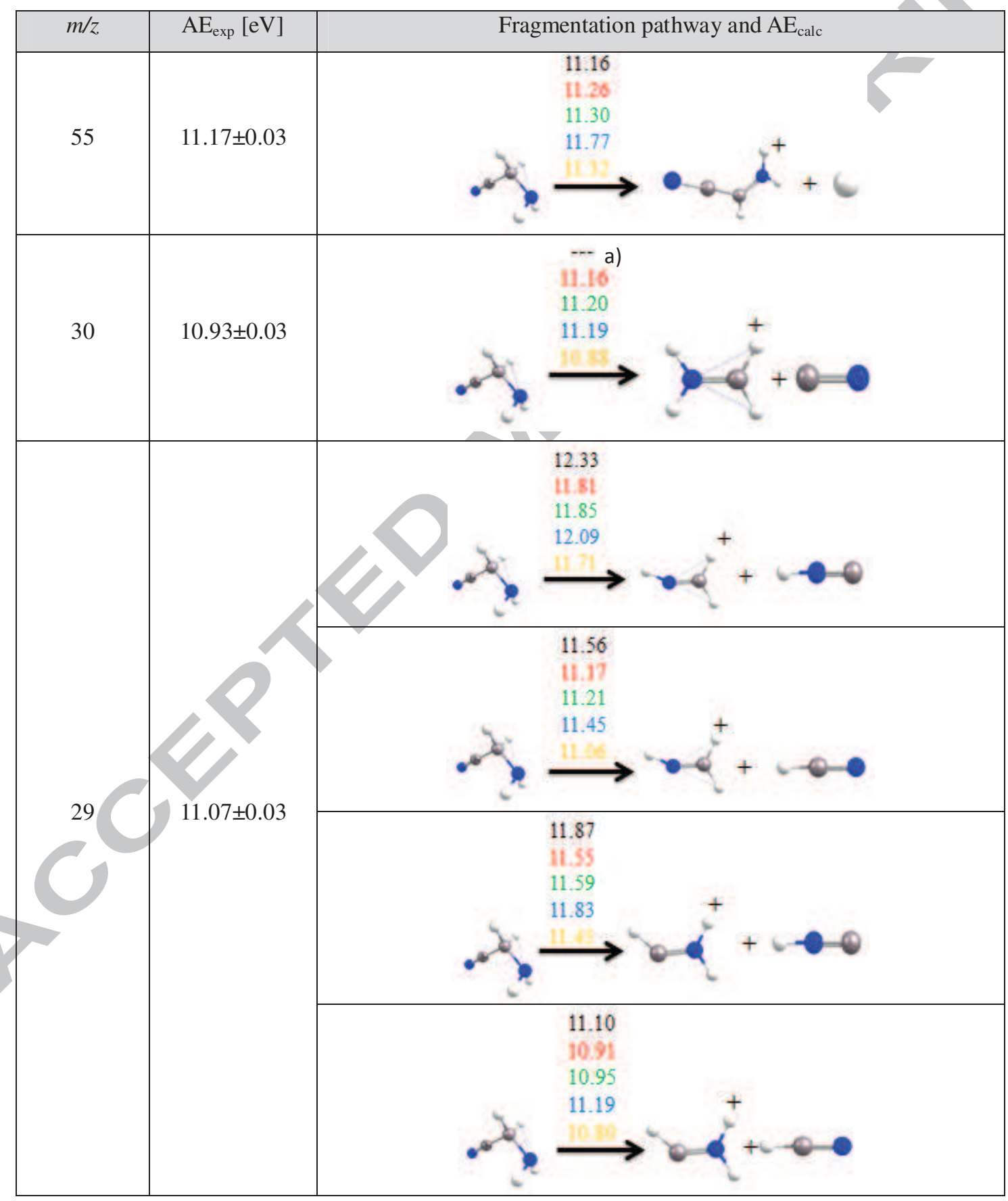




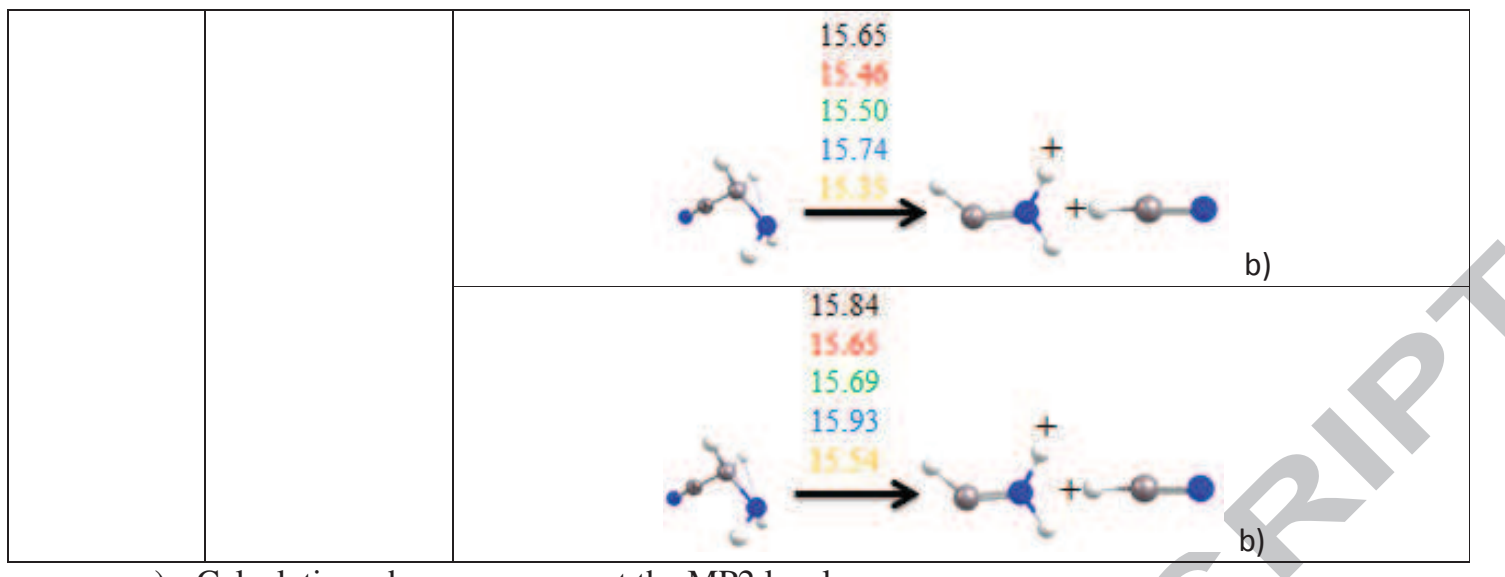

a) Calculations do no converge at the MP2 level.

b) The ionic fragment $\mathrm{HCNH}_{2}{ }^{+}$is formed in an excited state 
Table 2b: Experimental appearance energies $\left(\mathrm{AE}_{\mathrm{exp}}\right)$ of fragment ions with weak intensity observed in the dissociative photoionization of AAN. Calculated appearance $\mathrm{AE}_{\text {calc }}$, using five different methods, are given for different fragmentation pathways (color code see table 2a).

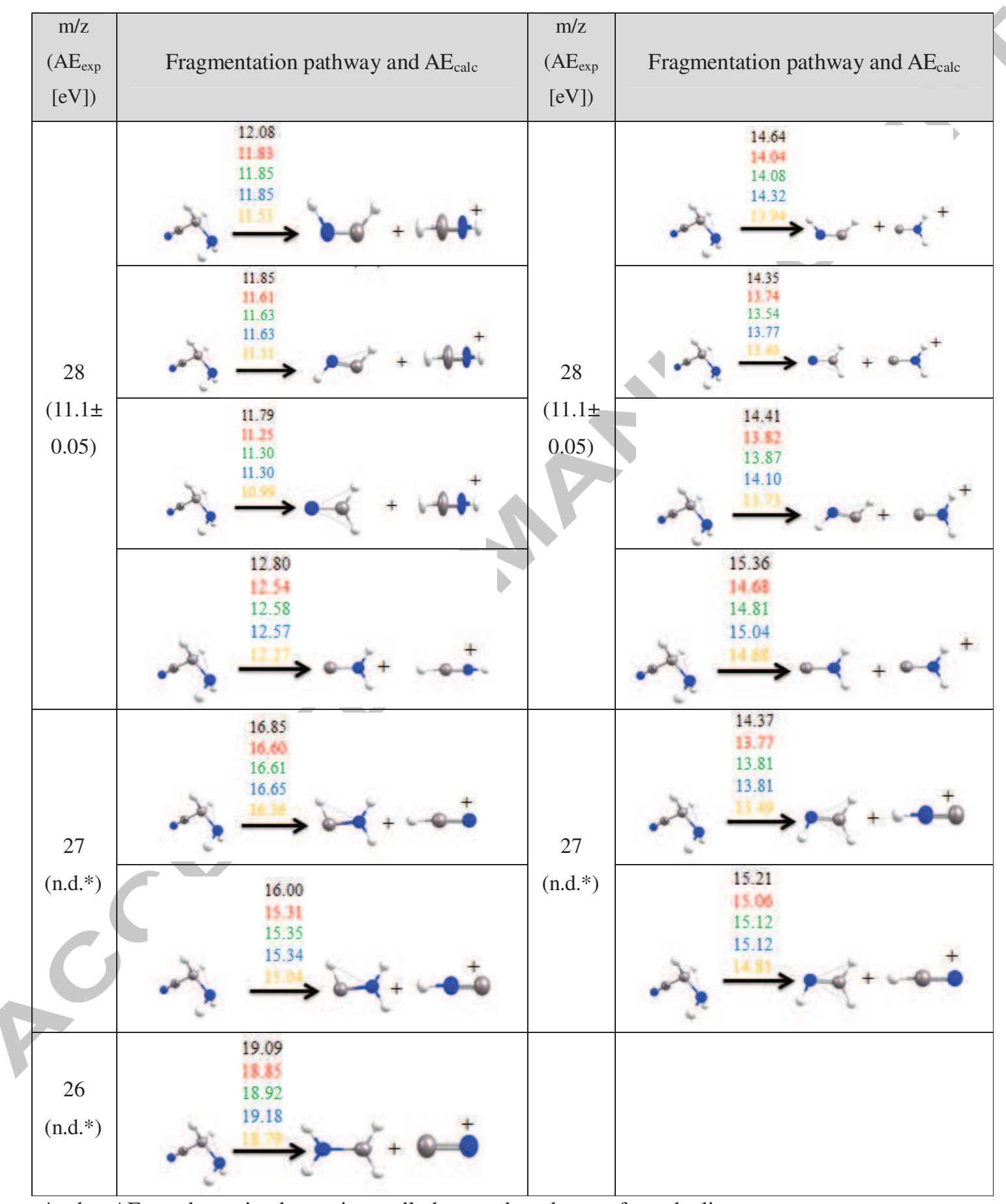

*n.d. = AE not determined experimentally here and not known from the literature 
VUV photoionization and dissociative photoionization spectroscopy of the interstellar molecule aminoacetonitrile: theory and experiment

Ayad Bellili et al.

Graphical abstract

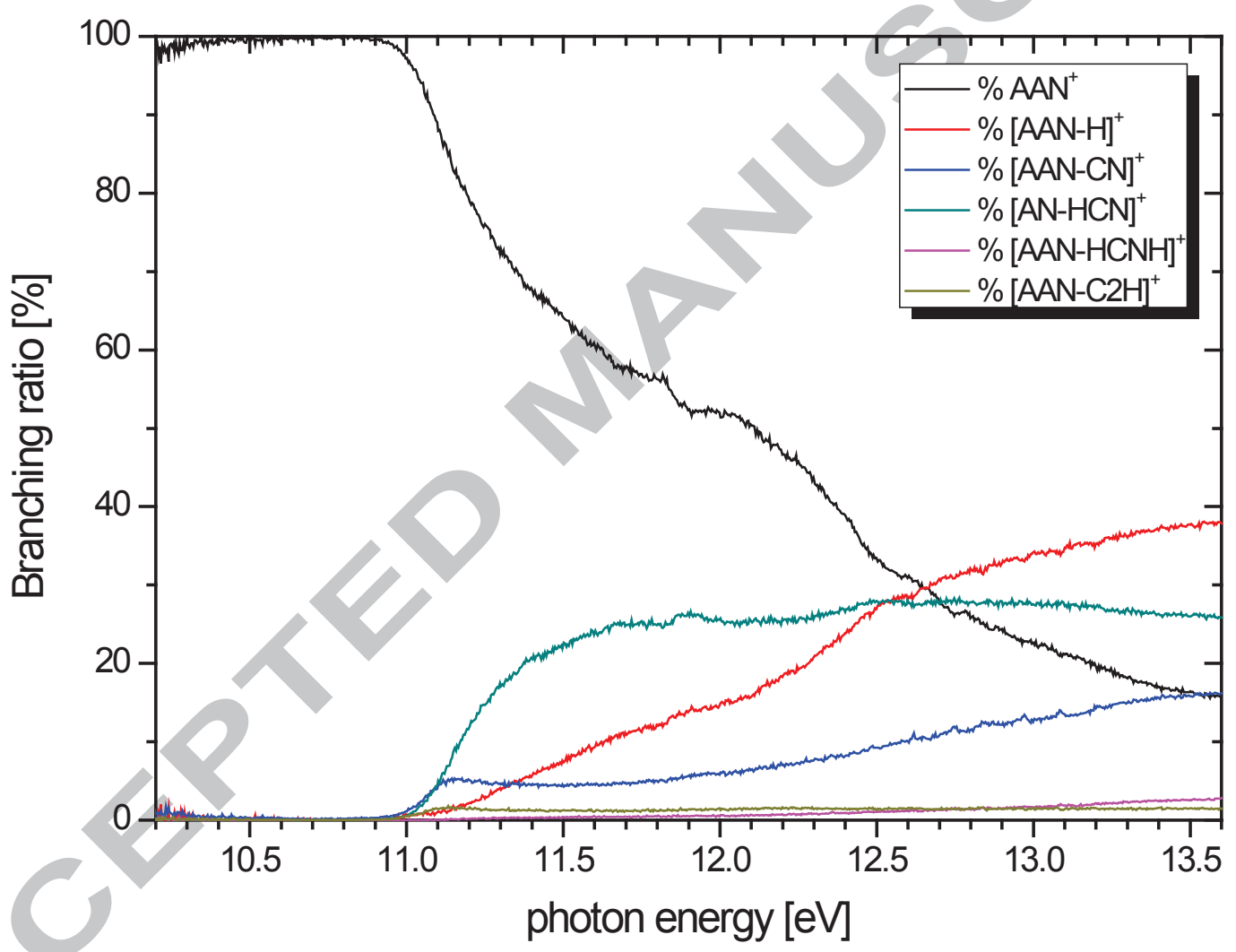

Photoionization of aminoacetonitrile $\left(\mathrm{H}_{2} \mathrm{NCH}_{2} \mathrm{CN}\right)$, a key compound in astrochemistry, yields 5 daughter ions in the 10 to $13.6 \mathrm{eV}$ energy regime. All threshold energies, including the ionization energy of the parent molecule, have been measured for the first time using synchrotron radiation. They are reproduced in this work by high level ab-initio quantum-chemical methods where numerous fragmentation pathways have been considered. 